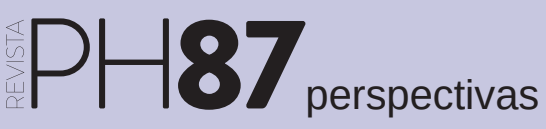

a debate Preexistencias en la ciudad histórica contemporánea: viabilidad y convivencia

| coordinan Plácido González Martínez, Miguel Ángel Tabales Rodríguez

\title{
El patio de mi casa es particular. La puesta en valor de restos arqueológicos en edificios residenciales de Córdoba
}

\author{
María Ibáñez Alfonso | grupo de investigación Historiografía y Patrimonio Andaluz (HUM 402), U. de Sevilla \\ Paola Romano Pringles | investigadora independiente \\ Moira Sotelo Rico | grupo de investigación ATLAS (HUM 694), Universidad de Sevilla
}

URL de la contribución <www.iaph.es/revistaph/index.php/revistaph/article/view/3592>

Córdoba, urbe milenaria que cuenta con un amplio y reconocido legado patrimonial, ha sabido conjugar en la última década tradición y modernidad apostando por la creación de nuevos espacios culturales que complementen a los ya consagrados Alcázar, Mezquita-catedral y los floridos patios, verdaderos hitos identitarios de la ciudad. Sin embargo, otros patios son los que llaman nuestra atención en esta ocasión; quizás no sean tan atractivos como aquellos, pero en su interior albergan testimonios de civilizaciones pasadas que, como parte

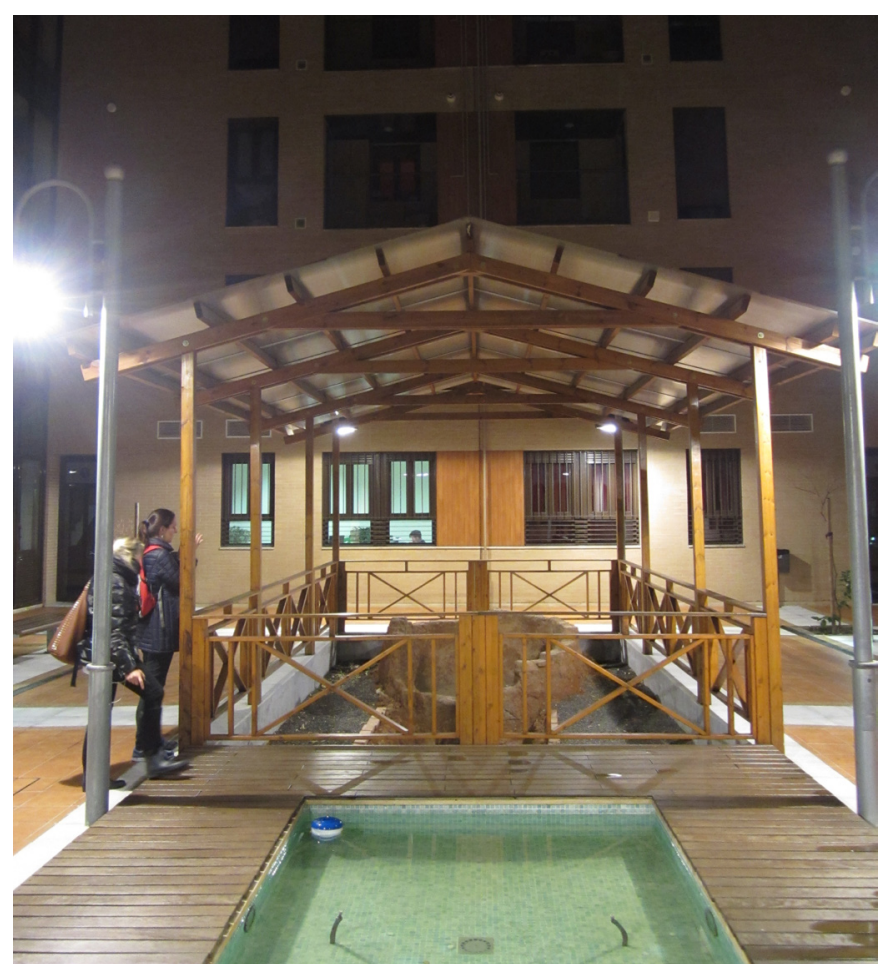

Edificio residencial Alfar. Horno árabe en el patio de acceso recubierto por una pérgola de madera protegida con una cubierta | foto María Ibáñez Alfonso consustancial de la riqueza histórica de la capital, deben ser valorados en su justa medida. Nos referimos a los numerosos ámbitos de carácter arqueológico que se han conformado dentro de edificaciones residenciales como consecuencia del auge de la construcción en los años de bonanza económica.

La aparición de hallazgos arqueológicos en el subsuelo es muy habitual en ciudades superpuestas como Córdoba, pero ¿qué hacer con esta ingente cantidad de vestigios? En la actualidad no existe un procedimiento estándar para evaluar la relevancia de los restos arqueológicos desde el punto de vista patrimonial (GONZÁLEZ; MÉNDEZ, 2000), por lo que su salvaguarda depende de las decisiones arbitrarias tomadas por los distintos agentes implicados en su gestión (en las que normalmente influyen una serie de presiones económicas, sociales e incluso políticas). No es exagerado afirmar que un nutrido sector de la población percibe aún estos elementos arqueológicos urbanos como algo negativo, un estorbo que paraliza las obras y retrasa la ejecución de los proyectos (reformados, documentación complementaria o anulación de licencia). Pese a ello, bien sea por imperativo, bien sea por propio interés, es cada vez más frecuente encontrarnos con ejemplos de restos emergentes que son integrados en bloques de viviendas privadas poniendo de manifiesto que el equilibrio entre el progreso y la conservación in situ es posible. Así pues, vestigios de diversa índole son exhibidos en zonas comunes como vestíbulos, jardines, patios y aparcamientos aportando un valor añadido al nuevo edificio.

Ahora bien, no deja de ser menos importante la necesidad de realizar un proyecto de puesta en valor coherente con los restos arqueológicos y sin dejar de lado el posi- 


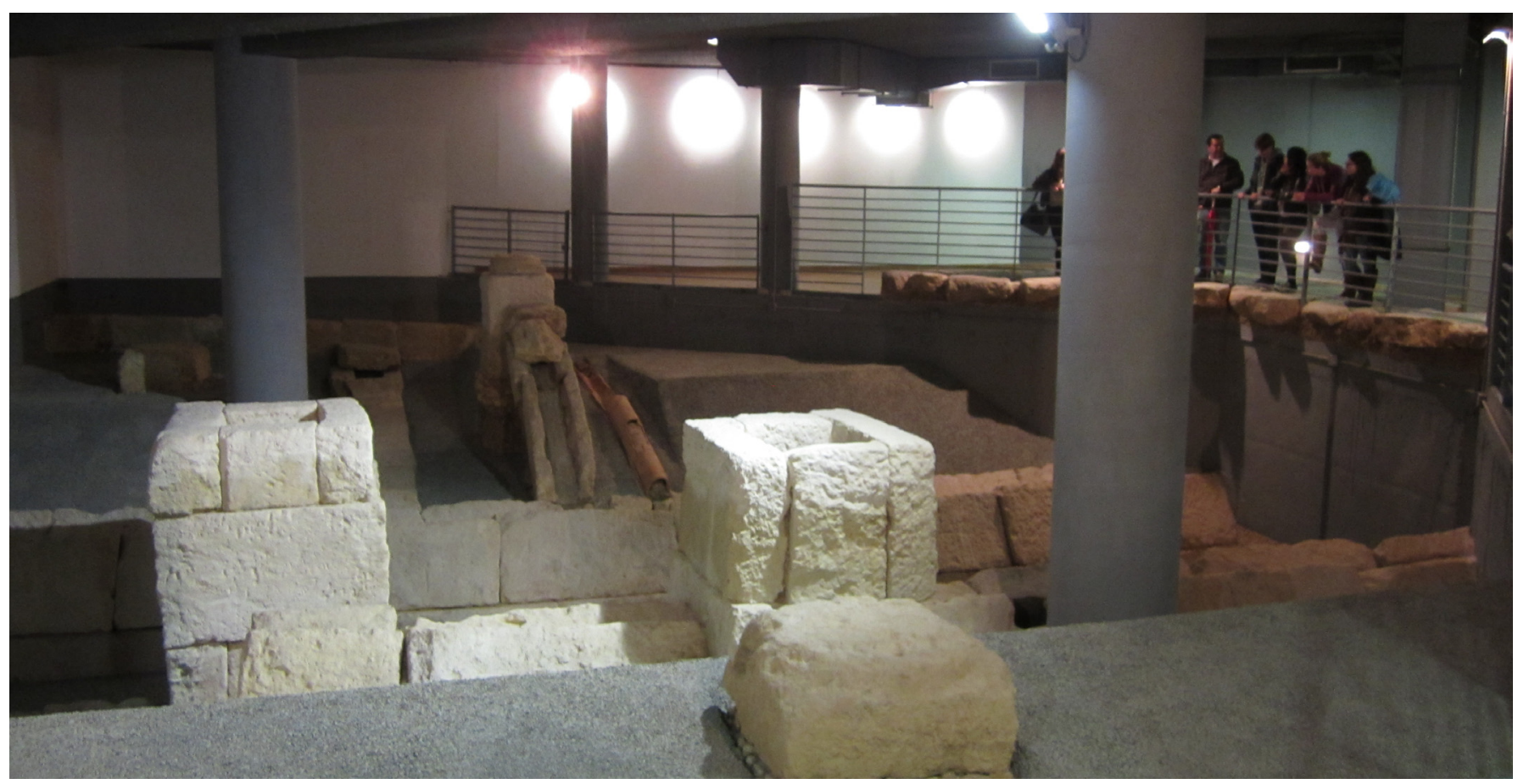

Edificio residencial en c/ Secretario Carretero. Cloacas romanas dentro de un recinto musealizado en el interior del aparcamiento subterráneo | foto María Ibáñez Alfonso

cionamiento de los mismos dentro de un contexto específico y privativo tales como son los edificios destinados a uso residencial. Es indispensable tener en cuenta la percepción de estos espacios tanto a nivel privado como público, puesto que los materiales utilizados para este propósito deben ser neutros y acordes a la zona en que se emplazan como así también la exigencia de un mantenimiento prácticamente nulo. De este modo consigue destacar dentro de un ambiente totalmente opuesto como el residencial; sin dejar de lado la posibilidad de albergar y permitir que puedan realizarse visitas de orden público como herramientas de apoyo al conocimiento de nuestro pasado (TAGLIABUE, 1993).

Se precisa una profunda reflexión, ya que existe un claro desequilibrio entre el proceso de restauración y la puesta en valor, con preocupantes deficiencias a la hora de transmitir información dado que carecen de la señalética adecuada para el reconocimiento de los mismos. En ciertos casos, pareciera pretender el ocultamiento de los hallazgos arqueológicos o privar a las personas de su existen- cia. Por otra parte, ofrecen una información detallada pero no acertada en cuanto al desarrollo de los mismos ya que los materiales utilizados se ven abocados en corto plazo a ser ininteligibles o presentar un proceso de deterioro acelerado que derivan en un estado negativo para las personas que hacen uso del mismo. Otro aspecto a tener en cuenta es su mantenimiento y conservación, ya que debería estar controlado por algunos de los agentes involucrados, tanto sea la propiedad o bien alguien designado por un organismo público. Tal es el caso del edificio residencial Alfar, donde la propia comunidad se encarga de estas funciones atendiendo a las directrices marcadas por la empresa que realizó su restauración.

Como ejemplos se podrían citar varios, aunque es difícil que un único espacio cumpla con todos los requisitos. Sin embargo, en cada uno existen características determinantes que lo hacen singular, como el de la calle Secretario Carretero, donde los restos arqueológicos cohabitan de forma armoniosa con el edificio residencial. 
En este contexto, es interesante destacar la cantidad de buenos ejemplos de integración de vestigios en edificios públicos y privados ${ }^{1}$, al menos desde el punto de vista de su descubrimiento y mantenimiento in situ, que se encuentran en la ciudad de Córdoba. Se puede decir que en los últimos años las políticas públicas han sabido acompañar el proceso de urbanización, donde se han desarrollado proyectos arquitectónicos que armonizaron sus diseños con la preservación de las huellas de la antigüedad.

Pero esto no se logra solamente a partir de las directrices de los técnicos. Los restos arqueológicos no son patrimonio sólo por ser restos y ser del pasado, son patrimonio cuando una comunidad se los apropia, los vive y los siente como parte de su historia. En este sentido, Córdoba parece tener una sensibilidad especial. Ha logrado que en ámbitos tan privados como el patio de una casa o una sala para hacer pilates se generen instancias particulares de protección. Este tipo de ciencia pública supone una forma de conocer y trabajar con el patrimonio, en la que confluyen la mirada de los científicos, los lugareños y otros actores involucrados. Apela a la apropiación social y a la construcción participativa del conocimiento arqueológico, implicando pensar formas de conocimiento desde/con y para la sociedad (VIENNI et ál., 2012).

Estos bienes, recuperados en suelos urbanos residenciales, cuyo valor es el de constituir conocimiento histórico y sentido de pertenencia, precisan de propuestas de puesta en valor y planes de gestión específicos para estas circunstancias, generados desde el entorno local. El desafío será la implicación de la comunidad, y su éxito radica en el reconocimiento que tenga como parte de su identidad.

\section{BIBLIOGRAFÍA}

- GONZÁLEZ MÉNDEZ, M. (2000) Sistemas de evaluación del interés patrimonial de yacimientos arqueológicos. En BÓVEDA LÓPEZ, M. (coord.) Gestión patrimonial y desarrollo social. Santiago de Compostela: Laboratorio de Arqueoloxía e Formas Culturais, IIT, USC, 2000, pp. 19-34 (CAPA; 12)

- TAGLIABUE, R. (1993) Architetto e Archeologo. Confronto fra campi disciplinari. Milano: Edizione Angelo Guerini e Associati, 1993

- VIENNI, B. et ál. (2012) Ciencia Pública en construcción: El Programa de Educación patrimonial y Ciencia Pública del LAPPU (FHCE). En IV jornadas de Investigación y III de Extensión de la Facultad de Humanidades y Ciencias de la Educación <http://www.fhuce.edu.uy/jornada/2011/Ponencias \%20Jornadas\%202011/GT\%2035/Ponencia\%20GT35\%20Vie nni\%20et\%20al.pdf> [Consulta: 30/01/15]

\section{NOTA}

1. Extracto de un trabajo de campo más amplio consistente en el análisis de la puesta en valor de elementos arqueológicos en edificaciones del casco urbano de Córdoba (noviembre, 2014). 